\title{
Redes sociales y oficios de justicia en Indias. Los vínculos de dos alcaldes mayores neogallegos
}

\author{
Celina G. Becerra Jiménez* \\ UNIVERSIDAD DE GUADALAJARA
}

Reconstrucción de la estrategia relacional del primero y el último de los alcaldes mayores que fueron nombrados desde Madrid para ejercer el oficio en el distrito neogallego de Santa María de los Lagos. Se analiza el tipo de vínculos que los magistrados establecen desde su arribo, como muestra su interés por insertarse en las redes de la elite local, así como la disposición de ésta para aceptar al recién llegado. A través de múltiples lazos con los personajes más activos y destacados de la elite local, el recién llegado, que no cuenta con experiencia en la administración de justicia en Indias buscaba legitimar su presencia y autoridad. Para ello cada uno de los representantes de la Corona constituye el centro de un tejido de relaciones sociales a través de las cuales se da un intercambio continuo de servicios y favores recíprocos.

(Alcaldía mayor, subdelegación, redes sociales, Nueva Galicia, Santa María de los Lagos)

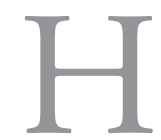

asta ahora se conoce poco sobre el perfil y las estrategias de actuación de los representantes de la Corona castellana que se desempeńaron como alcaldes mayores y corregidores en el Nuevo Mundo, un vacío difícil de explicar, en primer lugar, porque se trata de un conjunto amplio de individuos de muy diversos orígenes y desempeńos que a lo largo de tres centurias representaron el rostro del soberano ante los pobladores de villas, pueblos y campos y constituyeron la base del complejo aparato de la administración colonial en un imperio de dimensiones trasatlánticas. Por otra

*solbecmx@yahoo.com.mx 
parte, el papel clave de los gobernantes provinciales como instrumentos de control y dominio de los extensos territorios de las Indias ha sido demostrado en estudios sobre las elites y en análisis de los circuitos mercantiles. ${ }^{1}$ Sin embargo, son todavía escasos los trabajos dedicados a estas autoridades de nivel provincial, tanto en la Nueva España, como en la Nueva Galicia. ${ }^{2}$

Desde fines del siglo XVI, había sido atribución del gobernador del reino de la Nueva Galicia expedir los títulos de alcaldes mayores y corregidores en su territorio, una tarea que debía apegarse a las disposiciones de la legislación indiana y, al mismo tiempo, tomar en cuenta las realidades sociales imperantes. Así, desde temprana época, en la selección de los justicias ${ }^{3}$ para las provincias neogallegas intervenían tanto las relaciones e intereses del gobernador y su círculo más allegado, como los altos ideales de la Corona, como bien lo ha demostrado Thomas Calvo. ${ }^{4} \mathrm{Si}$ bien en los primeros momentos

${ }^{1}$ Thomas Calvo, "Círculos de poder en la Guadalajara del siglo xviı" en Familia y poder en Nueva España, México, Instituto Nacional de Antropología e Historia, 1991; Margarita Menegus, comp., El repartimiento forzoso de mercancías en México, Perú y Filipinas, México, Instituto Mora-unam, CESU, 2000.

${ }^{2}$ Woodrow Borah, El gobierno provincial en la Nueva España. 1570-1787, México, Universidad Nacional Autónoma de México, 1985; Celina G. Becerra Jiménez, Gobierno, justicia e instituciones en la Nueva Galicia. La alcaldía mayor de Santa María de los Lagos, Guadalajara, Universidad de Guadalajara, 2008. Otros trabajos que sin estar dedicados centralmente al análisis de estas instituciones abordan el tema son Agueda Jiménez Pelayo, "La carrera política de un gallego en Nueva Espańa. Manuel Vaamonde: de alcalde mayor de Sayula a gobernador del Nuevo Reino de León y Tlaxcala" en Celina G. Becerra Jiménez, coord., Elites, redes y vinculos en el Centro Occidente de México, Guadalajara, Universidad de Guadalaajara, 2008; Beatriz Rojas, Las instituciones de gobierno y la elite local. Aguascalientes del siglo XVII hasta la Independencia, Zamora, El Colegio de Michoacán, Instituto Mora, 1998; José Miguel Romero de Solís, Conquistas e instituciones de gobierno en Colima de la Nueva España (1523-1600), Colima, Archivo Histórico del Municipio de Colima, Universidad de Colima, El Colegio de Michoacán, 2007. A partir de 2007 el Seminario Interinstitucional sobre Gobierno Provincial convocado por Celina G. Becerra J. y Rafael Diego-Fernández reunió a investigadores interesados en el tema con el fin de presentar resultados de trabajo con nuevas fuentes y perspectivas. Se encuentra en preparación un volumen con los primeros resultados de este esfuerzo.

${ }^{3}$ El termino justicia aparece en las fuentes indistintamente para designar alcaldes mayores y corregidores, así como otros representantes de la Corona con autoridad jurisdiccional.

${ }^{4}$ Thomas Calvo, Poder, religión y sociedad en la Guadalajara del siglo XVII, México, Centre d'Études Mexicaines et Centraméricaines-H. Ayuntamiento de Guadalajara, 
se intentó establecer las bases para el funcionamiento de estas instituciones con apego a los principios establecidos, la realidad indiana y las dificultades económicas de la monarquía habían terminado por imponerse para dar lugar a una realidad que ha sido interpretada como una burocracia patrimonial donde sus integrantes recibían pagos en especie, propinas y productos de cohechos y sobornos; ${ }^{5} \mathrm{o}$ bien como un sistema donde la corrupción era una regularidad reflejada entre otras cosas en la participación de los alcaldes en actividades comerciales mediante el reparto de mercancías. ${ }^{6}$

Esta situación experimentó una transformación hacia $1674^{7}$ cuando, para aliviar la crisis de la Real Hacienda, se decidió conceder alcaldías mayores y corregimientos utilizando la figura jurídica del "beneficio", definida como la concesión regia de un cargo con jurisdicción, en compensación de una cantidad entregada voluntariamente por un particular en calidad de "servicio" al monarca. ${ }^{8} \mathrm{~A}$ partir de entonces se multiplicaron las posibilidades de que desde la península concedieran nombramientos por cinco ańos y no solamente uno como ocurría a aquellos que eran nombrados en Indias, a nobles, militares y otros personajes sin experiencia en asuntos de administración de justicia ni de de gobierno y que nunca habían estado en el Nuevo Mundo. ${ }^{9}$ Con esta nueva circunstancia cambiaron no sólo los perfiles de los magistrados, sino también la concepción de estos empleos como vía para hacer fortuna en el Nuevo Mundo, agravando la corrupción y alentando la participación de los titulares en empresas comerciales, cobros y exacciones a la población local. Por estos y otros medios, los beneficiados con oficios de justicia buscaban recu-

1992, 46-54.

${ }^{5}$ John Leddy Phelan, The Kingdom of Quito, p. 326.

${ }^{6}$ Horst Pietschmann, "Corrupción en la Indias Españolas: Revisión de un debate en la historiografía sobre Hispanoamérica colonial” en Horst Pietschmann, Mexiko zwischen Reform and Revolution. Vom bourbonischen Zeitalter zur Unabhängigkeit, Stuttgart, Steiner, 2000, 182.

${ }^{7}$ Angel Sanz Tapia, ¿Corrupción o necesidad? La venta de cargos de Gobierno americanos bajo Carlos II (1674-1700), Madrid, Consejo Superior de Investigaciones Científicas, 2009, 53-54.

${ }^{8}$ Fernando Muro Romero, "El beneficio de oficios públicos con jurisdicción en Indias. Notas sobre sus orígenes", Anuario de Estudios Americanos, xxxv, Sevilla, 1978, 2-3.

${ }^{9}$ Celina G. Becerra Jiménez, Gobierno, justicia e instituciones, pp. 243-244. 
perar una inversión onerosa que no se limitaba a la cantidad entregada a la Real Hacienda para obtener el título, sino que había que sumar los gastos del viaje, del registro de título ante las diversas instancias americanas y los gastos para establecerse en el nuevo destino. ${ }^{10}$

Con la llegada de los borbones al trono español se hizo presente una preocupación mayor por el desempeño de los magistrados en el nivel provincial y se dieron los primeros pasos encaminados hacia la creación de una burocracia más eficiente, esfuerzos que se tradujeron en novedades para los distritos del Nuevo Mundo que culminarían con la desaparición de los alcaldes mayores en $1786 .{ }^{11}$ Las novedades llegaron a la Nueva Espańa en 1786 con la expedición de la Real Ordenanza de Intendentes que suprimió las alcaldías mayores para organizar el territorio en jurisdicciones mucho más extensas, las intendencias, a cargo de un titular con atribuciones en las cuatro causas de justicia, guerra, policía y hacienda. Es bien sabido que entre los objetivos de la Corona estaba acabar con la corrupción y los abusos a que habían dado lugar los gobernantes provinciales y extinguir el repartimiento de mercancías. ${ }^{12}$ En adelante, los agentes de la monarquía en las antiguas alcaldías mayores serían los subdelegados, auxiliares que debían asistir al intendente en el desempeño de sus funciones. Sin embargo, los requisitos que debían reunir los subdelegados no quedaron establecidos en la Real Ordenanza $a^{13}$ y el único rasgo que menciona es que debían ser españoles, sin especificar si criollos o peninsulares, lo que luego daría lugar a ciertas discusiones. ${ }^{14}$ De manera escueta, la Real Ordenanza de 1786 establecía solamente que a medida que los alcaldes mayores terminaran sus funciones fueran sustituidos por un subdelegado. En cuanto a las

${ }^{10}$ Horst Pietschmann, "Burocracia y corrupción en Hispanoamérica colonial. Una aproximación tentativa (1983)" en Horst Pietschmann: Mexiko zwischen Reform and Revolution. Vom bourbonischen Zeitalter zur Unabhängigkeit, Stuttgart, Steiner, 2000, 157.

${ }^{11}$ Susan Socolow, The Bureaucrats of Buenos Aires, 1769-1810: Amor al Real Servicio, Durham, Duke University Press, 1987, 257.

${ }^{12}$ Ricardo Rees Jones, El despotismo ilustrado y los intendentes de la Nueva España, México, Universidad Autónoma de México, 1979, 167-168.

${ }^{13}$ Real Ordenanza para el establecimiento e instrucción de intendentes de ejército y provincia en el Reino de la Nueva Espańa. Madrid, 1786, art. 12.

${ }^{14}$ Beatriz Rojas, Las instituciones, p. 219. 
remuneraciones, la Ordenanza señaló los salarios de los intendentes y prohibió que recibieran cualquier otra cantidad por vía alguna, ${ }^{15}$ sin embargo, no mostró igual preocupación por el salario que deberían recibir los subdelegados. Finalmente éste quedó establecido, como había venido ocurriendo desde los primeros tiempos, en una pequeńa parte de los tributos, de apenas cinco por ciento. ${ }^{16}$

La venta de cargos habría agravado los abusos y corrupción que caracterizaron el desempeño de los alcaldes mayores y corregidores en Indias que desde el momento que accedían al oficio a través de la entrega de dinero a las arcas del monarca, se dedicaban a buscar la recuperación de la cantidad invertida hasta que la Real Ordenanza de Intendentes suprimió estos cargos y estableció que fueran los subdelegados a cargo de cada intendente los que desempeñaran las mismas funciones. ${ }^{17}$ En este sentido, el gobernante provincial posterior a la Ordenanza tendría que presentar notables diferencias con sus antecesores.

El estudio que aquí se presenta reconstruye la trayectoria del primer alcalde mayor del distrito neogallego de Santa María de los Lagos que fue nombrado por la vía del "beneficio real" con especial atención en las relaciones que estableció con la población local, para mostrar que fue capaz de generar una red de vínculos de tal amplitud que le permitió afianzar su autoridad y continuar con éxito una carrera en el gobierno provincial neogallego. Este caso es comparado con el del último alcalde mayor que gobernó Lagos, por nombramiento del monarca y que se distinguió, tanto por su larga permanencia en el empleo, como por haberse convertido en el primer subdelegado de este distrito. En ambos casos se ha buscado reconstruir las relaciones de confianza, compadrazgo, amistad y clientela a pesar de la pérdida de los archivos de la villa de Santa María de los Lagos y de su alcaldía mayor.

Se ha partido de la hipótesis de que un magistrado recién desembarcado en Indias, sin lazos familiares ni relaciones en la jurisdicción

${ }^{15}$ Real Ordenanza, 1786, art. 303.

${ }^{16}$ Real Ordenanza, 1786, art. 132.

${ }^{17}$ Horst Pietschman, Las reformas borbónicas y el sistema de intendencias en Nueva España, México, Fondo de Cultura Económica, 1996, 180-187. 
que debía gobernar, tendría que centrar sus esfuerzos en insertarse en las redes locales y especialmente en las de las elites dirigentes para lograr su aceptación, legitimar sus actuaciones y poder así desempeñar su papel de intermediario entre los intereses locales y los intereses de la monarquía. La construcción de su propio capital relacional dependía de lograr su integración en el círculo de los regidores de la localidad, de las familias de los criadores de ganado y terratenientes locales y de las autoridades eclesiásticas. De conseguir construir su propia red, el alcalde mayor estaría en condiciones de movilizarla para contribuir a sus propósitos cuando fuera necesario.

Al utilizar el enfoque de redes sociales y la elaboración de grafos, en los que a través de líneas se representa cada uno de los lazos detectados, se muestra que las reformas de 1786 no modificaron la diversidad y número de relaciones que construyeron los alcaldes mayores nombrados por la Corona, así como su capacidad para tejer una red muy extensa y difícil de captar en su totalidad. A través de vínculos estratégicos con personajes clave de las elites locales, lograban su incorporación a las redes sociales de la región indispensables para legitimar sus actuaciones y para construir su propia red.

\section{Un alCalde mayor de Santa María de los Lagos}

La alcaldía mayor de Santa María de los Lagos se localizaba al oriente del reino de la Nueva Galicia, en la frontera con la Nueva España y su titular era nombrado por el gobernador y presidente de la Real Audiencia de Guadalajara para ejercer el cargo por un año, con opción a ser prorrogado por otro más. Durante la segunda mitad del siglo XVII el cargo se concedió en varias ocasiones a comerciantes y terratenientes de las zonas vecinas de Zacatecas, Juchipila y Aguascalientes, quienes al mismo tiempo que tenían vínculos con las autoridades del reino, no resultaban desconocidos para los pobladores ni para los criadores de ganado que integraban el cabildo de la villa de Lagos. ${ }^{18}$ Otras veces, los encargados del gobierno provincial de este distrito eran designados entre personajes del entorno de los oidores

${ }^{18}$ Celina G. Becerra Jiménez, Gobierno, justicia e instituciones, pp. 241-243. 
y el gobernador, pero unos y otros coincidían en que habían tenido ya experiencia en la administración de otras jurisdicciones neogallegas. Esta situación habría de modificarse a partir de 1674 cuando la Corona decidió conceder oficios de justicia provincial en Indias por la vía del beneficio real.

El territorio se hallaba enclavado a medio camino entre Guadalajara y Zacatecas, en la región actualmente conocida como Los Altos de Jalisco. Se trata de una meseta con altitudes que van de los 1,600 a los 1,800 metros sobre el nivel del mar, cruzada por la cuenca del río Verde y sus afluentes los ríos Lagos y el Jalostotitlán. A orillas de este último se localizaba la mayor parte de la población tributaria asentada en varios pueblos de indios. La parte oriental, más alta, con escasa población a la llegada de los conquistadores por tratarse de un zona de paso para diversos grupos chichimecas, cruzada por el río Lagos que desciende de la sierra de Comanja, fue donde se fundó la villa de Santa María de los Lagos en 1563, que poco después pasó a convertirse en cabecera del que inicialmente había sido el corregimiento de Teocaltiche y los Pueblos Llanos. Tierras de pastos abundantes, pronto se poblaron con estancias productoras de ganado bovino, caballar y mular que se exportaba a la Nueva Espańa y a los reales de minas del norte, principalmente Zacatecas, San Luis Potosí y Real de Catorce.

El militar de origen vasco Felipe de Otaduy y Avendaño fue el primer alcalde mayor de Santa María de los Lagos con título expedido desde Espańa para un periodo de cinco años. ${ }^{19}$ Otaduy fue también el primero de los gobernantes de este distrito que llegó directamente desde la Península y pisó por primera vez tierra americana para tomar posesión de ese cargo. Su nombramiento, expedido en Madrid el 30 de diciembre de 1686, señalaba que se le concedía en virtud de sus méritos por haber servido con plaza de alférez en el ejército de Cataluña y Presidio de Ceuta durante diez ańos y que recibiría como salario los mismos 400 pesos anuales que se habían pagado a quienes le habían precedido en el cargo, "con el mismo salario y emolumentos que han gozado vuestros antecesores y en la

${ }^{19}$ Angel Sanz Tapia, ¿Corrupción o necesidad?, pp. 331. 
misma forma y manera que les hubiere gozado la persona que a la presente sirve por nombramiento de la dicha mi Audiencia”. ${ }^{20}$

A partir de la información que proporciona el título se concluye que no hubo entrega de donativo en moneda por parte del militar y que éste fue uno de los 18 títulos que la Corona concedió por servicios a otros tantos peninsulares el ańo 1686, fecha que marca la consolidación del sistema de beneficio de empleos en Indias, que había arrancado desde $1674 .^{21}$

El nuevo magistrado requirió más de un año para llegar hasta el lugar donde debía ejercer el cargo. El 29 de abril de 1687, presentó su título y prestó juramento solemne ante el Consejo de Indias y el 11 junio siguiente obtuvo licencia para pasar a las Indias. Una vez en México, presentó su nombramiento ante el virrey y cubrió los derechos para que quedara registrado en la secretaría del virreinato. No fue hasta el 6 de abril de 1688 que llegó a la Nueva Galicia y acudió ante la Real Audiencia de Guadalajara, cuyo presidente mandó que tomara posesión del oficio de inmediato, presentando el título ante el cabildo y regimiento de la villa de Lagos, aun cuando el capitán Juan Suárez de Estrada, alcalde mayor que se encontraba en el ejercicio de sus funciones con nombramiento del mismo presidente, no hubiera cumplido el tiempo para el que había sido provisto, so pena de mil ducados. Igualmente dispuso que al concluir los cinco años señalados, Otaduy habría de someterse a juicio de residencia ante esa Audiencia. ${ }^{22}$

El alferez Otaduy y Avendaño ya era un hombre casado cuando llegó a Lagos. Se estableció allí acompañado por su mujer Catalina del Baño y de la Cueva, de 26 ańos, "alta y delgada”, su hija Luisa de 8 ańos. Había realizado el viaje acompañado por dos criados solteros: Manuel Tacón, de 40 años, originario de Madrid, alto flaco y casi sin dientes e Ignacio Machaín de 21 años, mediano de cuerpo, blanco y delgado. ${ }^{23}$ Es probable que los dos últimos tuvieran poco

${ }^{20}$ Archivo General de Indias (AGI), Contratación, 5790, 1. 3, f.76f-82v.

${ }^{21}$ Angel Sanz Tapia, ¿Corrupción o necesidad?, p. 74.

${ }^{22}$ Archivo de Instrumentos Públicos del Estado de Jalisco (AIPJ), Libros de Gobierno (Gob.), volumen 23, documento. 41, f. 61f-73f.

${ }^{23}$ AGI, Contratación 5448, N.52. 
tiempo a su servicio. Ninguno compartía el mismo origen geográfico del militar y no existe evidencia que confirme la presencia de estos personajes en Lagos. En todo caso, se trataba de un reducido entorno familiar.

Para poder entrar al oficio todos los alcaldes mayores debían presentar garantías para asegurar a la Real Hacienda contra cualquier desfalco. Encontrar ese respaldo no representó un desafío para un recién llegado que traía bajo el brazo el título que le confería amplias competencias y atribuciones para gobernar el distrito durante los siguientes cinco años. Así lo demuestra el hecho de que, antes de emprender el camino a Lagos, Otaduy haya presentado como fiador al alférez real del cabildo de Santa María de los Lagos y uno de los vecinos más ricos de esa región, el capitán Diego de la Mota Padilla. Tan solo en 1688 este personaje había enviado desde su hacienda mil novillos y toros, ochocientos caballos y quinientas mulas para su venta en la Nueva España. ${ }^{24}$ Este terrateniente y criador de ganados, emparentado con familias de burócratas y terratenientes de la capital del reino, aceptaba comprometer sus haciendas y propiedades en garantía de que el recién nombrado cubriría los cargos que resultaran en su juicio de residencia, así como por los alcances que pudieran resultarle en el Juzgado de Bienes de Difuntos durante su mandato. La escritura para esta fianza fue signada por el propio Otaduy en virtud de un poder especial que para ello le había concedido Mota Padilla. La existencia de este poder que había sido expedido en el pueblo de Jalostotitlán, cercano a las propiedades del ganadero y que obraba en manos del recién llegado aun antes de que hubiera tomado posesión del cargo, revela el interés de las elites locales para establecer vínculos de confianza con los representantes de la Corona sin importar su procedencia. Un interés compartido porque ambas partes sabían que aseguraba beneficios. Al alcalde mayor, para insertarse en las redes que controlaban la política y la economía del distrito y a las familias de la elite que sabían que se trataba de una inversión que aseguraba los favores y buena voluntad del magistrado en los diversos asuntos donde su intervención era necesaria y, no

${ }^{24}$ AIPJ, Gob. vol. 23, doc. 117, f. 232v-234f. 
menos importante, la oportunidad para todos de participar de los rendimientos que ofrecían los oficios de gobierno provincial. ${ }^{25}$

Esta relación se fortaleció con el tiempo hasta llegar a establecerse un parentesco espiritual entre ellos en 1691, cuando el alcalde mayor invitó a Mota Padilla como padrino de bautismo de su hijo. Por otra parte, el recién llegado pronto logró incorporarse al círculo de las familias más influyentes en la economía y la política del distrito al convertirse también en compadre de Andrés Ramírez de Cueva y Sebastián de Sanromán de la Cueva y Rebollar, dos individuos emparentados entre sí y con largo historial en el cabildo de la villa por varias generaciones. Ambos ostentaban título de capitán y formaban parte de la elite alteńa de "modestos señores de ganados". El primero, personaje de avanzada edad, desde 1658 había tenido repetidas actuaciones en la corporación municipal como alcalde ordinario y procurador, cargos que había combinado con el de teniente de alcalde mayor. Sanromán, nieto del anterior se desempeñaba como alcalde ordinario de la villa a la llegada de Otaduy. Su última participación como miembro del cabildo se registró en 1704. Estaba casado con Beatriz Moreno de Ortega, hija y hermana de regidores con múltiples intereses como dueños de haciendas, criadores de ganado mayores y menores. Los Moreno de Ortega eran socios en diversos negocios de otros capitulares como Diego Flores de la Torre y Fulgencio González de Ruvalcaba. Estos vínculos resultarían muy valiosos para la carrera del alcalde mayor una vez terminadas sus funciones en la villa mariana y su jurisdicción, pues fue gracias a la fianza que Ramírez y Sanromán prestaron al militar peninsular en 1693, que éste pudo tomar posesión del oficio de alcalde de la Santa Hermandad que consiguió de la Real Audiencia de Guadalajara. ${ }^{26}$ En la figura 1 se aprecia que los vínculos con Mota Padilla, Ramírez y Sanromán permitieron la incorporación del nuevo alcalde mayor a las redes de sociabilidad que incluían a otros regidores y alcaldes ordinarios como los Esquivel Vargas, los Moreno de Ortega y los Rodríguez Portugal, así como a las autoridades eclesiásticas repre- 


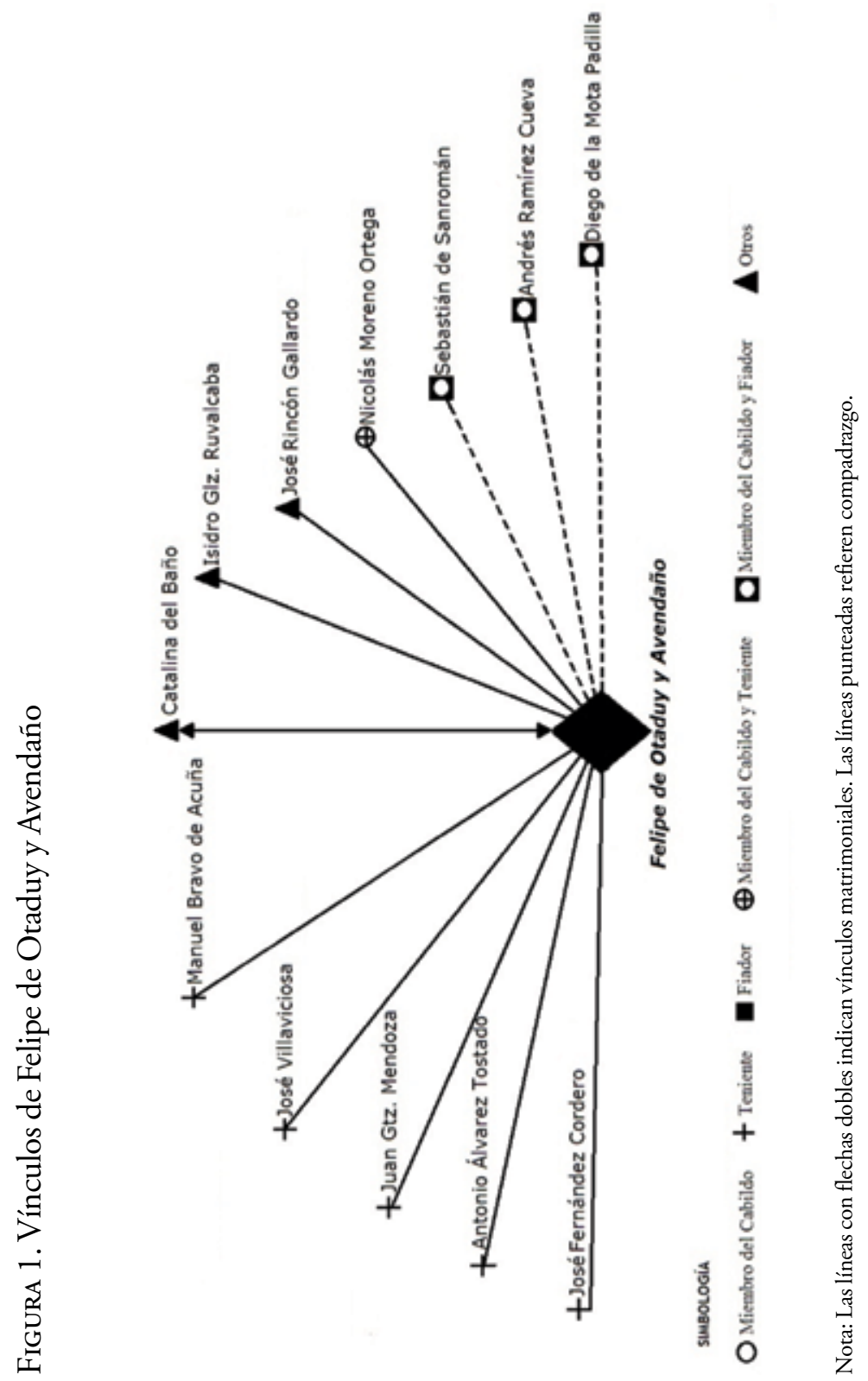


sentadas por el cura beneficiado de la villa, el bachiller Bartolomé Robles y el vicario y juez eclesiástico de la misma, licenciado José Moreno de Ortega cuñado de Sanromán.

Tales vínculos rendían beneficios a ambas partes. Para el magistrado recién llegado era indispensable conseguir la aceptación y apoyo de los miembros del cabildo de la villa, verdadero bastión de los intereses locales, cuyos integrantes mantenían el control sobre el territorio ${ }^{27} \mathrm{y}$, además, contaban con un valioso instrumento para todo gobernante: el conocimiento del espacio y de las relaciones y conflictos entre sus habitantes. La mayoría de los integrantes de las corporaciones municipales en Indias accedían a sus oficios a través de la compra y a menudo los trasmitían a sus herederos, por lo que su permanencia era mucho más prolongada que la de los alcaldes mayores. A esta condición se agregaba, en el caso de la villa de Santa María de los Lagos, el privilegio real que gozaba su cabildo, por el que sus jueces cadañeros tenían competencias sobre todo el territorio de la alcaldía y no sólo en la cabecera, situación que exigía una constante negociación y acuerdos sobre lo que la ley y la costumbre marcaban en este caso como ámbitos de la justicia ordinaria y del justicia mayor. A cambio de su apoyo al titular de la justicia en el distrito, los capitulares laguenses obtenían ventajas significativas para sus negocios y actividades ganaderas, agrícolas y comerciales.

Sin embargo, a pesar de los esfuerzos para tejer relaciones y asegurar apoyos, éstos se podían perder en cualquier momento y siempre habría dificultades que enfrentar y voluntades que no se lograban conquistar. Tal fue el caso que generó una alianza entre varios integrantes del cabildo en 1692 en contra del alcalde Otaduy y Avendaño, enfrentamiento que alcanzó tal magnitud que llegó hasta la Real Audiencia. La escasa documentación conservada da cuenta de que los regidores Martín Zermeño y Diego Guerra Valadez contaron con el apoyo de Diego Flores de la Torre, otro de los propietarios de haciendas y ganados, descendiente de los antiguos encomenderos de Juchipila y cuyo padre había desempeñado el oficio de alcalde mayor en varias jurisdicciones neogallegas, entre ellas

${ }^{27}$ Celina G. Becerra Jiménez, Gobierno, justicia e instituciones, pp. 316-317. 
la de Lagos. Los dos primeros habían interpuesto una demanda contra Otaduy ante la Audiencia y fue Flores de la Torre quien suscribió escritura como fiador de ellos para garantizar que se procedería conforme a derecho a lo largo del proceso. ${ }^{28}$ No hay información para conocer los pormenores ni el desenlace del asunto, pero se puede señalar que a pesar de que Flores de la Torre era suegro del alférez Mota Padilla, uno de los aliados más cercanos al alcalde mayor, decidió tomar partido con el bando contrario.

Los alcaldes mayores podían nombrar asistentes que les representaran en puntos lejanos a la cabecera o bien que les reemplazaran durante sus ausencias o enfermedades. En Lagos y en otros distritos había sido costumbre que los justicias que tenían propiedades e intereses fuera de la provincia que gobernaban se ausentaran con frecuencia, dejando en su lugar a un teniente, previa autorización de la Audiencia de Guadalajara. A cambio de la licencia para ausentarse y nombrar un teniente, los alcaldes servían a la Corona con cantidades que fluctuaron entre los ocho y los doce pesos. La figura del teniente, ya fuera general o de partido, tuvo un papel relevante entre los colaboradores del alcalde mayor por tratarse de su auxiliar más cercano, en el que podía delegar la mayoría de sus funciones. Desde épocas muy tempranas el tenientazgo había tenido un importante papel en la administración del los territorios americanos por ser la vía que permitía equilibrar los intereses locales con los de la capital del reino y constituía una instancia de poder y autoridad con arraigo en villas y provincias. ${ }^{29}$

Debe insistirse en que el nombramiento de teniente implicaba beneficios e ingresos para quien lo recibía. Los tenientes representaban al alcalde mayor en asuntos judiciales y le asistían en el cobro de tributos, en medidas de tierras y en diversos asuntos. Además recibían querellas en su nombre y actuaban como jueces receptores de testimonios e informaciones y para la expedición de testamentos y poderes. Como consecuencia de lo anterior, se establecía un lazo de solidaridad y confianza mutuas entre el titular del distrito y sus auxi-

${ }^{28}$ AIPJ, Gob. vol. 8, doc. 175, f. 339f-341f.

${ }^{29}$ José Miguel Romero de Solís, Conquistas e instituciones de gobierno, p. 234. 
liares, de tal manera que puede decirse que uno de los conductos más importantes para la negociación entre un alcalde recién llegado y la población local eran los tenientes que siempre se reclutaron entre los miembros de la elite: el cabildo de la villa ${ }^{30}$ y los terratenientes más importantes de la jurisdicción. Aunque no se han localizado evidencias de que el oficio se obtuviera en Lagos mediante la entrega de una cantidad de dinero al alcalde mayor, esa posibilidad no debe descartarse. Con esto se habría creado otro punto de interés compartido: ambos funcionarios tendrían como uno de sus objetivos, la recuperación del capital invertido.

Para atender cabalmente las responsabilidades inherentes a su oficio, los antecesores de Otaduy habían recurrido a dos tipos de auxiliares: los tenientes de partido y el teniente general. Los primeros residían en los dos pueblos más importantes de la alcaldía, Jalostotitlán y Nuestra Señora de San Juan, porque así sus habitantes no tenía que desplazarse hasta la villa cabecera o esperar la visita del alcalde para denunciar un delito o para realizar una diligencia. El teniente general, por su parte, era aquel que el alcalde mayor nombraba para que tomara su lugar en caso de ausencia o enfermedad, por lo que estaba investido de las mismas atribuciones que el titular. Su término en el cargo dependía de la voluntad del alcalde mayor y concluía en el momento en que éste terminaba sus funciones, excepto en caso de su fallecimiento, pues entonces quedaba a cargo del distrito hasta la llegada del sucesor. Los tenientes no tenían salario asignado y recibía sólo los derechos correspondientes a sus actividades como jueces receptores o a su participación en procesos judiciales. ${ }^{31}$

La aparición de los nombramientos por la vía del beneficio real representó para Lagos la llegada de un militar sin experiencia de gobierno y sin conocimiento de la tierra y sus gentes, para quien la colaboración de los tenientes resultaba aún más importante como mediadores indispensables que se convirtieran en su fuente de información y el enlace sus gobernados. El teniente formaba parte de

${ }^{30}$ José Miguel Romero de Solís, Conquista e instituciones de gobierno, p. 236.

${ }^{31}$ Woodrow Borah, El gobierno provincial, p. 55. 
la misma comunidad y contaba con amplio conocimiento de las familias, las propiedades, los negocios y las rencillas y bandos del lugar. El perfil de los tenientes de Otaduy y Avendaño muestra que se buscaba a individuos con experiencia en el gobierno y la impartición de justicia como aquellos que ya habían desempeñado el cargo con anterioridad o bien los regidores o alcaldes ordinarios del cabildo de la villa. Así, al poco tiempo de su arribo, Otaduy y Avendaño eligió a terratenientes de la localidad para que le auxiliaran en los partidos de Jalostotitlán y San Juan, si bien sólo conocemos a quienes desempeñaron sus funciones en el primero de estos pueblos donde nombró a Antonio Álvarez Tostado, al capitán Juan Gutiérrez de Mendoza y a José Fernández Cordero..$^{32}$ Álvarez Tostado había sido teniente del alcalde Suárez de Estrada, antecesor de Otaduy y pertenecía a una de las primeras familias españolas avecindadas en la región. El capitán Gutiérrez de Mendoza también era descendiente de los primeros pobladores de valle de Jalostotitlán y dueños de estancias y labores de tierra, ${ }^{33}$ mientras que Fernández Cordero estaba emparentado con escribanos reales de Guadalajara y junto con su hermano el bachiller Agustín, cura beneficiado de Jalostotitlán y los Mota Padilla, era un activo hombre de negocios que participaba en los remates de diezmos de Lagos y de otras parroquias de la zona. ${ }^{34}$

Para atender los asuntos que surgían en la cabecera de la alcaldía y sus alrededores, Otaduy nombró otro teniente de partido en Nicolás Moreno de Ortega, ${ }^{35}$ propietario de la estancia de Santa Teresa, próspero criador de ganados y miembro de uno de los clanes con amplia trayectoria en el cabildo mariano donde había servido como alcalde ordinario desde 1674 cuando había sido propuesto como uno de los vecinos "más nobles de aquella república y más hacenda-

32 AIPJ, Protocolos de Notarios (Prot.), Protocolos de José López Ramírez (JLR), vol. 5, f. 138f; vol. 6, f. $96 f$.

${ }^{33}$ AIPJ, Ramo Tierras y Aguas (TA), 25-2, exp.11.

${ }^{34}$ Celina G. Becerra Jiménez, Oficios de justicia en una sociedad ganadera de la Nueva Galicia. Santa María de los Lagos. 1563-1750, Tesis del Programa de Doctorado en Ciencias Sociales, El Colegio de Michoacán, 2004, 122.

${ }^{35}$ AIPJ, Gob. vol. 7, doc. 154, f. 156v-164v. 
dos de ella y dignos todos de la ocupación y honra de dichas varas y otras cosas del servicio de Su Majestad". ${ }^{36}$

Este nombramiento representaba la alianza entre el magistrado y una familia cuyos miembros acaparaban no sólo los oficios del gobierno temporal sino también los del ámbito espiritual a través del licenciado José Moreno de Ortega, vicario y juez eclesiástico de la parroquia de Lagos y el pueblo de Nuestra Señora de San Juan. ${ }^{37}$ La red de sociabilidades de esta familia era muy amplia, tejida mediante alianzas matrimoniales, compadrazgos y actividades ganaderas y comerciales y llegó a incluir a la mayoría de las familias de la elite local.

Para el oficio de teniente general Otaduy se decidió por un vecino de Santa María de los Lagos que contaba con experiencia en tareas de gobierno y justicia pues había ocupado este mismo cargo en 1683. Se trataba del peninsular José Villaviciosa, mercader que había llegado a la región en la década de 1670 y se integró a la elite primero mediante su matrimonio con Josefa López de Lara, descendiente de las familias más antiguas de la villa. Tras enviudar, Villaviciosa contrajo nuevas nupcias que le permitieron ingresar en otra de los troncos familiares de los primeros vecinos y con presencia dominante en el cabildo laguense desde mediados del siglo xvir. Su segunda esposa, Nicolasa de Anda Altamirano era hija de uno de los tratantes de ganado más ricos, el capitán Pedro Anda Altamirano quien, en 1641, había pagado quinientos pesos por el título de alférez mayor. En 1656, la Real Audiencia de Guadalajara había expedido el título de "justicia mayor" de Lagos a este personaje, que en ese momento se desempeñaba como alcalde ordinario, "en el interín que se nombre a la persona que desempeñará ese cargo" ${ }^{38}$ Las alianzas matrimoniales de los Anda Altamirano incluían varias familias de la elite local como los Moreno de Ortega y una muestra de los

${ }^{36}$ AIPJ, Gob. vol. 2, doc. 242, f. 1319 f-320v.

${ }^{37}$ Celina G. Becerra Jiménez, Oficios de justicia..., pp. 402-404.

${ }^{38}$ Celina G. Becerra Jiménez, "Familia y vínculos en un cabildo neogallego. Santa María de los Lagos. 1600-1750" en Manuela Cristina García Bernal y Sandra Olivero Guidobono, coords., El municipio indiano: relaciones económicas y sociales. Homenaje a Luis Navarro García. Sevilla, Universidad de Sevilla, 2009, 75. 
vínculos que tenía la familia tuvo lugar en 1676 cuando el matrimonio de Villaviciosa con Nicolasa contó como padrino al alcalde mayor en funciones, integrante de la elite tapatía y pariente de las autoridades del reino. La buena relación de Villaviciosa con su familia política se demuestra en sus actuaciones como albacea de su suegra, ${ }^{39}$ lo mismo que en su elección como procurador del cabildo laguense en 1689, al mismo tiempo que su cuńado Lorenzo de Anda Altamirano era elegido alcalde ordinario. Tres años más tarde el cabildo lo elegiría de nuevo procurador de la villa, cargo que combinó con el de teniente general.

Para 1691, la estrategia del alcalde mayor en cuanto a la elección de su auxiliar para el partido de Jalostotitlán cambió al preferir al capitán Manuel Bravo de Acuña ${ }^{40}$ por encima de los vecinos de la localidad. Para entonces, los intereses de Otaduy ya estaban puestos en el centro minero neogallego más importante: la ciudad de Zacatecas y no descansaría hasta llegar a realizar su sueño de convertirse en su corregidor. Bravo de Acuña pertenecía a una familia de exitosos plateros zacatecanos, que ese mismo año vería coronados sus esfuerzos con el título de Conde de Santa Rosa. El fundador del clan, Bartolomé Bravo de Acuña había logrado acumular su capital gracias a la introducción de técnicas novedosas para el desagüe de sus minas y su hijo, Juan Bartolomé, además de convertirse en el primer conde de Santa Rosa, llegaría a ostentar los títulos de Provincial de Santa Hermandad, Mesta y Cañadas de la Nueva Galicia y de teniente de capitán general de las Provincias del mismo reino. ${ }^{41} \mathrm{Al}$ establecer relaciones con el capitán Bravo de Acuńa, Otaduy lograba ingresar en la red de los grandes mineros zacatecanos, un mundo donde las oportunidades, para un representante del rey interesado en labrar una fortuna particular, eran mucho más atractivas que en un distrito ganadero como Lagos.

Todos los tenientes del alcalde mayor Otaduy, incluido Bravo de Acuña, eran terratenientes con intereses en la cría y exportación de

${ }^{39}$ AIPJ, Prot. Protocolos de José Antonio Calleja (JAC), vol. 1, f.310v-311v.

${ }^{40}$ AIPJ, Gob. vol. 7, doc. 206, f. 237f-238f.; Prot. Protocolos de Miguel Tomás de Ascoide (MTA), vol. 2, f. 120f-v.

${ }^{41}$ Agueda Jiménez Pelayo, Haciendas y comunidades indígenas, p. 117. 
bovinos a la Nueva Espańa, actividad central en la economía de la meseta alteña. Con frecuencia, la Real Audiencia comisionaba al alcalde mayor en turno como juez de registro encargado de contar el número de cabezas que cada ganadero sacaba de la Nueva Galicia para su venta en el reino de la Nueva España y por el que el exportador debía pagar las licencias correspondientes. La actuación del juez de registro resultaba crucial para aumentar el margen de ganancia de los exportadores y daba oportunidad al funcionario para favorecer o perjudicar a los involucrados. Aunque no se conservan registros completos de estas actividades, sabemos que Otaduy y Avendaño estuvo a cargo de vigilar que las exportaciones autorizadas en 1689 a los ganaderos alteños se ajustaran al número de animales registrado en las respectivas licencias. La experiencia que el alcalde mayor adquirió en temas pecuarios durante los cinco años que estuvo en Lagos y las relaciones que estableció con los productores de la zona le permitieron, una vez que había dejado el oficio, representar los intereses de algunos de los criadores de la región como el capitán José Rincón Gallardo, dueño del mayorazgo de Ciénega de Mata, quien le contrató en 1693 para negociar el pago de los diezmos que adeudaban todas sus haciendas con el cabildo eclesiástico de la Catedral de Guadalajara. ${ }^{42}$ Asimismo, la especialización de Otaduy en temas relativos a la ganadería, hizo posible sumar una comisión, que le concedió la Audiencia de Guadalajara como alcalde de Mesta y Cañadas, al oficio de alcalde mayor que desempeñaría más tarde en Jerez y Tlaltenango.

La amplitud y variedad de los vínculos que aparecen reflejan la capacidad de Otaduy para construir una red que constituyó un apoyo no sólo durante su mandato en la alcaldía alteńa sino para continuar actuando como servidor de la Corona. Así, aun cuando había varias acusaciones pendientes sobre comercio en el juicio de residencia y que no se había pronunciado sentencia alguna que lo declarase libre de todo cargo, las relaciones del militar peninsular con las autoridades de Guadalajara lograron que se le concediera en ese mismo año el título de alcalde de la Santa Hermandad y, en los años siguien-

${ }^{42}$ AIPJ, Prot. MTA, vol. 3, f. 29f-31v. 
tes, diversas comisiones como juez de medidas en Lagos y algunos distritos vecinos hasta que, en junio 1695, fue provisto como alcalde mayor de la villa de Jerez y valle de Tlaltenango. ${ }^{43}$ Esto es prueba tanto de sus buenos vínculos en la capital del reino, como de la pervivencia de los que había establecido desde su llegada a las Indias, pues, si en 1693 había sido su compadre Andrés Ramírez quien había dado fianza de que daría residencia como alcalde de la Santa Hermandad, para este nuevo cargo quien se comprometió como aval fue el capitán Sebastián de Sanromán de la Cueva y Rebollar. Por otro lado, mientras desempeñaba este oficio no dejaba de representar intereses de sus aliados laguenses solicitando para ellos licencias para exportación de ganado y realizando diversos trámites. ${ }^{44}$

Después de concluido el segundo año de prórroga para la alcaldía mayor de Jerez y Tlaltenango, el 6 de junio de 1698 la Audiencia le concedió el mismo título para el distrito de Aguascalientes. ${ }^{45}$ Lo único que sabemos sobre su desempeño es que en 1701, al concluir el juicio de residencia correspondiente, se le impuso una multa de 510 pesos junto con su teniente, Julián Antonio de Mendoza, y su escribano, Salvador Delgado. Entre las relaciones que estableció en esta última provincia estuvieron las que permitieron regresar a establecerse en la cabecera de Aguascalientes al final de su vida ${ }^{46}$ y, además, las que permitieron que su hija Luisa contrajera matrimonio con Miguel Martín Barragán, comerciante y propietario de la hacienda de Cańada Honda y alférez real en el cabildo de esa villa. ${ }^{47}$

A pesar de que el primero de los monarcas de la casa de Borbón intentó terminar con los abusos generados por la concesión indiscriminada de empleos con administración de justicia en $1701,{ }^{48}$ Otaduy logró el ascenso que por años había buscado al convertirse

${ }^{43}$ AIPJ, Gob. vol. 11, doc. 95, f. $142 \mathrm{f}$.

${ }^{44}$ AIPJ, Gob. vol. 11, doc. 110, f. 161f-162f.

${ }^{45}$ AIPJ, Gob. vol. 14, doc. 93, f. 178v.

${ }^{46}$ Carmen Paula Palomo Sousa, "Los corregidores de Zacatecas: una elite de poder (1700-1786)" en Luis Navarro García, coord., Elites urbanas en Hispanoamérica (De la conquista a la independencia), Sevilla, Universidad de Sevilla, 2005, 125.

${ }^{47}$ Beatriz Rojas, Las instituciones, p. 136.

${ }^{48}$ Angel Sanz Tapia, "Provisión y beneficio de cargos políticos en Hispanoamérica (1674-1700)", Jahrbuch für Geschichte Lateinamerikas, 37, 2000, 27. 
en corregidor de Zacatecas en 1702. Las circunstancias parecen indicar que tomó posesión del empleo antes de que en Nueva Espańa se conociera y empezara a aplicarse la nueva disposición, situación muy afortunada para el vasco pues aunque se ordenaba impedir la toma de posesión a aquellos que hubieran obtenido títulos por beneficio real, quedaban exentos quienes que ya se encontraran ejerciendo sus funciones. Las circunstancias en las que logró llegar al cargo estuvieron llenas de contratiempos y dificultades. Algunas fuentes señalan que Otaduy obtuvo el título pagando 12,000 pesos a José de Villaurrutia, quien lo había conseguido desde 1695 y lo renunció en el militar vasco alegando su imposibilidad para embarcarse desde la península hasta Zacatecas debido a su avanzada edad. Esta subrogación, común en los oficios que otorgaba la Corona, habría sido aprobada por el Consejo en febrero de $1700 .{ }^{49}$ En otros testimonios se habla de que el interesado sirvió con una cantidad de 7,000 pesos para las arcas del rey. ${ }^{50}$ En cualquier caso, ambas cantidades confirman la capacidad de los magistrados para obtener ganancias en los empleos que desempeñaban, lo mismo que de la presencia de unos vínculos indispensables a ambos lados del Atlántico para obtener uno de los mejores corregimientos americanos, cuyo salario ascendía a mil pesos ensayados, ${ }^{51}$ pero cuyo mayor atractivo radicaba en los rendimientos que se obtenían de su numerosa población y su intensa actividad platera.

El nuevo oficio estuvo lleno de problemas y dificultades que fueron el rasgo dominante del paso del Otaduy y Avendaño por Zacatecas. Si logró librarse de las disposiciones del monarca para impedir que tomaran posesión quienes hubieran beneficiado títulos y aún no estuvieran en uso del cargo, más difícil le resultaría enfrentar la oposición de los vecinos de la ciudad minera, hasta quienes habían

${ }^{49}$ José Enciso Contreras, "Decretos inhibitorios, justicia privativa provincial y local. El caso del conde de Santa Rosa en Zacatecas (S. XVIII)" Derecho, instituciones y procesos históricos. XIV Congreso del Instituto Internacional de Historia del Derecho Indiano, en José de la Puente Brunke y Jorge Armando Guevara Gil, eds., tomo II, Lima, Pontificia Universidad Católica del Perú-Instituto Riva-Agüero, 2008, 378.

${ }^{50}$ Carmen Paula Palomo Sousa, "Los corregidores de Zacatecas”, p. 131.

${ }^{51}$ Angel Sanz Tapia, ¿Corrupción o necesidad?, p. 407. 
llegado noticias de que en los juicios de residencia del antiguo alcalde de Lagos y Aguascalientes habían surgido acusaciones de comportamientos arbitrarios y abusivos contra lo población y se opusieron a la transacción que había hecho con Villaurrutia. ${ }^{52}$

A pesar de las circunstancias adversas, una vez instalado en su nuevo destino el antiguo militar debió hacer uso de sus habilidades para relacionarse con la elite local, pero esta sociedad minera y sus principales pobladores presentarían más obstáculos para el experimentado magistrado que los que había encontrado en cualquiera de sus destinos anteriores. Sus alianzas no resultaron exitosas y, desde su llegada, tuvo enfrentamientos con los poderes locales. ${ }^{53}$

Los esfuerzos del Otaduy para afianzar su posición contaban con sus antiguos vínculos con la familia Bravo de Acuña gracias a los cuales, desde 1696, se había convertido en compadre de uno de los zacatecanos más ricos, el primer conde de Santa Rosa al invitarle a bautizar a su hija. Ese mismo año había tenido oportunidad de mostrar su apoyo al conde al enviarle maíces desde Tlaltenango para que no murieran de hambre los trabajadores de sus minas y haciendas a causa de la grave escasez que se presentaba y, al mismo tiempo, se convirtió en intermediario del empresario zacatecano para la compra de tierras. A cambio de sus servicios el conde permitía que pastara en su hacienda de Santa Rosa del Malpaso un importante hato de ganado propiedad de Otaduy. La situación cambió poco después cuando el inicio del siglo XVIII marcó la ruina de la casa de Santa Rosa agobiada por las deudas y los enormes gastos necesarios para mantener la producción de las minas, al punto que su titular tuvo que renunciar incluso al uso del título por no poder pagar el derecho de lanzas a la Corona. En la lista de acreedores aparecía el nombre del corregidor que reclamaba 2,500 pesos de los maíces que le había proporcionado años atrás y llegado el momento no dudó en mandar un apoderado a exigir el pago de la suma a su compadre. ${ }^{54}$

${ }^{52}$ AGN, Indiferente General, caja 741, exp. 26.

${ }^{53}$ Carmen Paula Palomo Sousa, "Los corregidores de Zacatecas”, p. 130.

${ }^{54}$ José Enciso Contreras, "Decretos inhibitorios”, pp. 380-381. 
Las dificultades financieras del noble zacatecano dieron pie a medidas extraordinarias desde la capital del virreinato con el fin de mantener a flote la producción de las minas y asegurar el pago de las deudas que tenía del conde de Santa Rosa con la Real Hacienda. La más importante de estas medidas sería un decreto inhibitorio limitando la jurisdicción de cualquier justicia respecto de todas las causas, civiles y criminales, relativas a la mina de Benitillas. Expedido en 1703 por el virrey duque de Albuquerque, el decreto limitaba la autoridad del corregidor de Zacatecas sobre las minas y los trabajadores del conde y nombraba como administrador de todos ellos a don Pedro de Salazar y Águila, quien hizo entrega del documento a Otaduy y Avendaño. El enfrentamiento entre el corregidor y el representante de la jurisdicción del virrey no se hizo esperar y durante tres años la estabilidad de Zacatecas y su distrito se vio alterada por las disputas entre estos dos personajes que pusieron todo su empeño en impedir las labores del adversario a través de toda clase de procedimientos y acusaciones mutuas.

A través de los autos que dan cuenta de la resistencia que el corregidor opuso a la inhibitoria, se observa que desde su llegada al centro minero se habían registrado roces y enfrentamientos con oficiales reales y otros vecinos de la ciudad que se oponían a que tomara posesión del oficio. Además, sus enemigos acusaban a Otaduy de una serie de faltas que incluían la organización de juegos de azar en su propia casa, el rescate de metales en la mina Benitillas, la evasión del pago del quinto real, de actuar injustamente y de tener deudas con la Real Hacienda. Señalaron además que permitía que un criado de Julián de Mendoza, aliado de Otaduy desde sus años en Aguascalientes, usurpara la cobranza de alcabalas en Vetagrande y que habiéndole aprehendido los oficiales reales, Otaduy había permitido que escapara de la cárcel de Zacatecas. ${ }^{55}$

$\mathrm{Al}$ ver que los informes que había enviado al virrey no obtenían la respuesta esperada, ${ }^{56}$ a principios de noviembre de 1704 el corregidor decidió viajar a Guadalajara, donde contaba con aliados de

${ }^{55}$ José Enciso Contreras, "Decretos inhibitorios”, pp. 377-396.

${ }^{56}$ AGI, Guadalajara, 157. 
quienes podía esperar apoyo, para presentarles sus argumentos y abandonó el centro minero sin dejar siquiera teniente que en su representación atendiera los asuntos diarios. Al abandonar la ciudad perdió el espacio de autoridad que aún le quedaba, pero sus buenas relaciones con las autoridades del reino lograron que la Audiencia enviara a Zacatecas a su pariente, Fernando Hurtado de Mendoza, con título de teniente, quien se haría cargo de continuar la guerra contra los representantes del virrey, Salazar de Águila y los oficiales reales. El alcalde mayor finalmente partió rumbo a España quizá con la esperanza de que fueran escuchadas sus críticas a la que calificaba como una decisión injustificada del virrey.

La disputa habría de continuar todavía por varios años hasta que, en 1710, el corregidor pudo volver Zacatecas gracias a una orden de la Real Audiencia de Guadalajara para que se restituyera en el cargo hasta cumplir su periodo de cinco años. Unos meses antes este mismo tribunal había sentenciado y condenado al pago de cien pesos de multa a don Pedro de Salazar y Águila en el juicio que éste había promovido contra Otaduy, por haber encontrado que había sido aquel quien había requisado indebidamente 46 marcos de plata, por lo que le condenó al pago de 100 pesos de multa. ${ }^{57} \mathrm{Al}$ parecer, los lazos tejidos por el corregidor zacatecano con autoridades neogallegas se mantuvieron todavía varios años lo que le valió comisiones como la de juez de residencia del gobernador de la Nueva Vizcaya, Manuel de San Juan en $1720 .^{58}$

La trayectoria de Felipe de Otaduy y Avendaño desde su llegada a las Indias y su recorrido a través de diversos oficios de gobierno en la Nueva Galicia demuestra que el establecimiento de vínculos con la sociedad local constituyó una parte esencial de la estrategia de los magistrados que llegaban por vez primera a las Indias para consolidar y legitimar su autoridad. La elección acertada de personajes que tenían un papel central en las redes de sociabilidad locales resultaba crucial para poder insertarse en ellas. Aunque las fuentes disponibles no permiten identificar lazos con los pobladores de las repúblicas de

${ }^{57}$ AIPJ, Gob. vol. 12(2), doc. 486, f. $116 f$.

${ }^{58}$ AGI, Escribanía de Cámara, L. 391B. 
indios debemos suponer que varios de sus integrantes formaron parte de las relaciones del alcalde que seguramente buscaría también entre ellos aquellos individuos que resultaban claves para el control de esos espacios sociales.

A través del apoyo que los justicias mayores brindan a las actividades e intereses de sus aliados en el cabildo de la villa y en los pueblos de indios, hacían sentir la presencia de un monarca preocupado por la felicidad de sus súbditos y conseguían, a cambio, aceptación, beneficios económicos y apoyos necesarios para el desempeño de sus tareas y para asegurar un desempeño exitoso.

Desde su arribo Otaduy puso su empeńo en tender lazos con los miembros más influyentes en la alcaldía de Lagos, aquellos que controlaban la economía y la política en la región y logró una red que le sirvió como base para lanzarse a obtener oficios redituables hasta conseguir el corregimiento de Zacatecas. Sus vínculos con las autoridades neogallegas no fueron menos importantes. Aunque no contamos con evidencias para reconstruirla, su red con oidores y funcionarios tapatíos debió funcionar como un sólido respaldo, sólo así se explican los sucesivos nombramientos para oficios provinciales a pesar de resultar con acusaciones diversas en las respectivas residencias y el apoyo que recibió de las autoridades neogallegas durante la larga disputa por el decreto de inhibición jurisdiccional.

\section{De alCALde MAYOR a SUbDELEgado}

Trece de los 25 alcaldes mayores que gobernaron Santa María de los Lagos entre 1688 y 1792, fecha de su transformación en subdelegación, obtuvieron el título por nombramiento expedido en la metrópoli. De estos trece alcaldes, ocho fueron los que arribaron a la meseta alteña directamente procedentes del Viejo Continente, sin contar con experiencia previa en asuntos de gobierno y justicia. El militar vasco Felipe de Otaduy y Avendaño fue el primero y el cubano Francisco Javier Arriola sería el último. ${ }^{59}$

${ }^{59}$ Celina G. Becerra Jiménez, Gobierno, justicia e instituciones, p. 246. 
Entre los individuos que obtuvieron el título para el distrito de la villa mariana por la vía del beneficio regio predominaron individuos con carrera en las armas, que justificaban su solicitud para ingresar al gobierno provincial tanto en el valor y fidelidad que habían demostrado hacia la Corona, como en el donativo a las arcas reales de cantidades que oscilaron entre los mil y los tres mil pesos. ${ }^{60}$ Otaduy y Avendańo, sin embargo, obtuvo el oficio de alcalde mayor de la villa de Lagos sin que mediara entrega de dinero para el real erario, sólo en virtud de sus servicios de diez años como alférez. ${ }^{61}$ Otros cinco alcaldes laguenses, además de servir con cantidades que fluctuaron entre los mil y los tres mil pesos, presentaron méritos y servicios en la Armada del Mar Océano, en el ejército de Cataluña o en otros cuerpos militares. La Corona desapareció el beneficio de cargos en 1750 , pero después de esta fecha llegaron a la meseta alteña varios alcaldes nombrados desde la metrópoli en virtud de sus servicios o méritos. El último de ellos se distinguió porque nunca estuvo en los ejércitos europeos, sino en los de su natal Cuba. ${ }^{62}$

Francisco Javier Arriola había nacido en La Habana en 1731, descendiente de españoles originarios de la isla de Cuba y de la Nueva España, todos "cristianos viejos y limpios de toda mala raza de moros, judíos y mulatos". ${ }^{63}$ Inició su carrera militar a la edad de 17 años como parte de la tripulación de la escuadra que defendía las costas del Mar de las Antillas de los enemigos de la Corona. Desde entonces había participado en diversos enfrentamientos contra embarcaciones inglesas y francesas, donde resultaría herido en más de una ocasión. Más adelante sentó plaza como cadete de regimiento e inició un recorrido que le llevaría del antiguo batallón de La Habana al nuevo regimiento de Infantería donde obtuvo los grados de alférez de granaderos. En 1762, con motivo del sitio inglés a La Habana, durante la Guerra de los Siete Años, participó en la defensa de las fortalezas de El Morro, Cabaña y Punta. Dos años después

${ }^{60}$ Celina G. Becerra Jiménez, Gobierno, justicia e instituciones, p. 245.

${ }^{61}$ AGI, Contratación, 5790, L. 3, f. 76f-82v.

${ }^{62}$ Archivo General de Simancas (AGs), España, Secretaría del Despacho de Guerra (sGU), 6966, exp. 8 f. 21-27.

${ }^{63}$ AGs, 6966. Indiferente 154, N.4. 
viajó a España para presentar una relación de méritos ante la Secretaría del Consejo de Indias, pero al parecer sus gestiones no alcanzaron el objetivo deseado de manera inmediata y regresó a su ciudad natal en calidad de edecán del mariscal de campo y gobernador de la plaza don Diego Antonio Manrique. ${ }^{64}$

Es de suponer que el militar cubano insistió en solicitar algún oficio de justicia en Indias. No hay certeza si volvió a viajar a Espańa para hacer las diligencias necesarias o si contó con algún patrocinio para llegar a los agentes que se ocupaban de presentar las peticiones de los aspirantes a la Cámara de Indias, pero en consulta del 27 de noviembre de 1771 se le concedió la alcaldía mayor de Santa María de los Lagos y Pueblos Llanos del distrito de la Audiencia de Guadalajara sin mediar servicio pecuniario y sólo en virtud de sus servicios. El título de Francisco Javier de Arriola fue despachado el 8 de marzo de 1773, cuando el interesado se encontraba de nuevo en Madrid, donde presentó juramento ante el Consejo de Indias el 29 del mismo mes. Realizados los preparativos para el viaje, el 7 de julio siguiente se le concedió licencia para embarcar en Cádiz acompañado solamente por su esposa y un negro esclavo, natural de La Habana, que había llevado con él, de nombre Juan José Arriola, así como con los baúles de ropa, libros "y lo demás acostumbrado". ${ }^{65}$

Tras las consabidas escalas en México y Guadalajara, tomó posesión del oficio en la villa de Santa María de los Lagos el 12 de febrero de $1774 .{ }^{66}$ Aquí habría de desempeñarse como alcalde mayor por un periodo excepcional para la época y para todas las Indias, que rebasaría los veinte años, para luego convertirse en su primer subdelegado. Una vez concluido su largo periodo al servicio del rey, permaneció en Lagos hasta su muerte ocurrida en $1799 .{ }^{67}$

El título de Arriola, como el de todos los alcaldes mayores neogallegos de beneficio real, establecía que el titular debía desempeñar el cargo durante cinco años, por tanto debió concluir sus funciones y presentarse a juicio de residencia en 1779 para permitir que tomara

\footnotetext{
${ }^{64}$ AGS, SGU, 6966, exp. 8.

${ }^{65}$ AGI, Contratación, 5518, N.2, r. 16.

${ }^{66}$ AGI, Guadalajara, 354.

${ }^{67}$ AGI, Contratación, 5518, N.2, r. 16.
} 
posesión su sucesor, ya fuera provisto por el monarca o por las autoridades neogallegas. Sin embargo lo que ocurrió fue totalmente distinto. Arriola continuó al frente del distrito hasta 1797 y la única residencia de que se tiene noticia fue presentada en agosto de 1789, fecha que hace suponer que cada quinquenio se expidió un nuevo título aunque no se ha localizado ninguna prueba documental de ello. Una relación de los individuos que estaban a cargo en las subdelegaciones de la Intendencia de Guadalajara, elaborada alrededor de 1791, señala que Arriola seguía en el cargo en virtud del nombramiento de 1773, si bien se desconocen las circunstancias que permitieron que la misma persona se mantuviera tantos ańos. ${ }^{68} \mathrm{La}$ misma fuente señala claramente que ni el primer intendente de Guadalajara Antonio de Villaurrutia, ni su sucesor Jacobo de Ugarte y Loyola, el autor de dicha relación, habían expedido nombramiento alguno para el distrito laguense. Queda entonces abierta una interrogante acerca de los factores que pesaron más para su prolongado gobierno ¿la fuerza de sus vínculos en Lagos o sus buenas relaciones con las autoridades de Guadalajara?

Lo cierto es que en 1792, al presentar su relación de méritos, el propio Arriola declaró haber administrado justicia en la villa de Lagos y su jurisdicción como alcalde mayor provisto por Su Majestad durante 16 años, más otros dos en los que se había desempeñado con el ambiguo título de "justicia mayor" nombrado por "el superior gobierno e intendencia de Guadalajara”.

Los intendentes de Guadalajara sostuvieron una larga disputa en defensa de su derecho a proveer los subdelegados de sus distritos sin intervención del virrey de la Nueva España. ${ }^{69}$ Si bien no se ha localizado el título de Arriola, existe una notificación, con fecha de 24 de noviembre de 1795 dirigida a la Real Audiencia en la que se lee "Habiendo nombrado a don Francisco Javier de Arriola para que sirva el empleo de subdelegado de la jurisdicción de Lagos lo participo a Vuestra Señoría para que se sirva hacerlo presente a la Real

${ }^{68}$ AGI, Guadalajara, 354, N.8.

${ }^{69} \mathrm{Ma}$. de los Ángeles Gálvez, La conciencia regional en Guadalajara y el gobierno de los intendentes. 1786-1800. Guadalajara, unED, 1996, 43-46. 
Audiencia. Dios Gurarde a Vuestra Señoría Muchos Años. Jacobo Ugarte y Loyola". ${ }^{70}$

Por otra parte, en varios documentos fechados en ese mismo ańo, se le designa como "subdelegado en las cuatro causas de justicia, policía, hacienda y guerra" ${ }^{71}$ funciones que mantuvo hasta 1797 cuando fue nombrado su sucesor, Manuel Castelazo y Parodi.

Al llegar a su destino sin más colaboradores que un sirviente para su servicio personal, Francisco Javier Arriola tuvo que recurrir a la población local para establecerse con el decoro que exigía su posición y obtener los servicios necesarios para el desempeño de sus funciones. Por el juicio de residencia que presentó en 1789 (véase figura 2) sabemos que para entonces el número de tenientes que había empleado a lo largo de esa década ascendía a doce, cantidad que no parece excesiva si se considera el aumento de habitantes y de extensión territorial que había experimentado la antigua alcaldía durante esa centuria. Mientras en 1760 se reportaban 17,467 habitantes sólo en el curato de Santa María de los Lagos, uno de las tres parroquias que había en el distrito, para 1797 eran 27,503. La misma villa mariana reflejaba claramente esta situación al haber pasado de aproximadamente 2,000 a 5,660 habitantes entre estas dos fechas. ${ }^{72}$ Además, el militar cubano tuvo que ejercer sus funciones sobre un territorio más extenso que sus antecesores, pues el territorio del antiguo corregimiento de Teocaltiche con sus cuatro pueblos de indios y sus numerosos puestos y haciendas se había incorporado al distrito laguense desde $1790 .^{73}$

La estrategia de los representantes de la Corona para elegir a sus hombres de confianza no había variado con respecto a la que había seguido Otaduy nueve décadas atrás. A su llegada Arriola nombró como teniente para Jalostotitlán a Juan Manuel de la Peña vecino de ese pueblo, quien volvería a ocupar el oficio en varias ocasiones. Aunque no es posible precisar la situación debido a la pérdida de los

${ }^{70}$ BPE, Civil, 1795, s/c.

${ }^{71}$ Archivo del Arzobispado de Guadalajara (AAG), Gobierno, Parroquias, Unión de San Antonio, caja 1.

${ }^{72}$ Celina G. Becerra Jiménez, Gobierno, justicia e instituciones, p. 130.

${ }^{73}$ Celina G. Becerra Jiménez, Gobierno, justicia e instituciones, p. 268. 
archivo del alcalde mayor, algunos indicios sugieren que el alcalde nombraba tenientes cada ańo. En 1777 quien aparece con ese cargo es uno de los hacendados más ricos de la región, Cayetano Macías Valadez, capitán de la Primera Compañía de Infantería Española de Fusileros de las establecidas Provinciales y quien ese año ejercía también las funciones de alcalde ordinario de la villa de Lagos. ${ }^{74}$

En 1785, el oficio de "teniente de la Real Justicia por el seńor don Francisco Javier de Arriola, alcalde mayor y de la Santa Hermandad de la Villa de Santa María de los Lagos y su jurisdicción con el agregado de los Pueblos Llanos y Teocaltiche por Su Majestad" estaba en manos de Ignacio de la Garza Falcón, ${ }^{75}$ también vecino del pueblo de Jalostotitlán que había adquirido una de las haciendas más productivas de la zona y estaba emparentado con uno de los oidores de Guadalajara. ${ }^{76}$ Garza Falcón estaba casado con una hermana de Macías Valadez y continuaba en el oficio en 1787. Sin embargo, en 1793 de la Peña había vuelto a ocupar ese cargo, en el que permanecería hasta la salida de Arriola. ${ }^{77}$

Como teniente en el pueblo de Nuestra Señora de San Juan, el justicia mayor colocó a un comerciante bien conocido en Lagos y Aguascalientes, Mariano del Árbol y Bonilla, propietario de una hacienda y miembro de la corporación municipal de esta última villa. Había contraído matrimonio con una de las hermanas del mayorazgo Rincón Gallardo, poseedor de Ciénega de Mata, uno de los latifundios más extensos de la Nueva Galicia. Los Rincón Gallardo habían mantenido una presencia constante en los oficios de justicia de Aguascalientes y Lagos para asegurar el beneficio de sus numerosos intereses en la región. Durante la primera mitad del Xviı sus antepasados habían adquirido oficios de cabildo y consiguieron las alcaldías mayores de los dos distritos. Desde el gobierno de Otaduy, habían optado por establecer alianzas con los magistrados provinciales para asegurar su apoyo en todos los asuntos relacionados con sus negocios.

${ }^{74}$ Archivo de la Real audiencia de Guadalajara (ARA), Civil, c. 447, exp. 1, \# 7359, f. $27 \mathrm{f}$.

${ }^{75}$ AAG, Gobierno, Parroquias, Jalostotitlán, caja 1.

${ }^{76}$ AGI, Guadalajara, 106.

${ }^{77}$ ARA, Civil, c. 447, exp. 1, \# 7359, f. 406 f. 
Arriola acostumbró nombrar un auxiliar para atender a los vecinos de la cabecera del distrito. El primero del que se tiene noticia fue Baltazar de Meza y Buenaño, tapatío con buenas relaciones en el cabildo catedralicio ${ }^{78}$ y bien conocido por los laguenses porque había desempeñado el cargo de teniente general durante varios años desde 1747, cubriendo las ausencias por enfermedad del alcalde en turno, y porque en 1752 el gobernador neogallego le había nombrado "justicia mayor de la villa de Santa María de los Lagos y su jurisdicción”. Meza y Buenaño residía en la villa mariana mientras otros miembros de su familia administraban una hacienda en el territorio vecino de Aguascalientes. ${ }^{79}$ Para 1783, el teniente de Arriola en la villa era Juan de Anaya, un personaje con muy diversos intereses y actividades en el territorio alteño. Había nacido en 1732 en El Tortuguero, un rancho del curato de Jalostotitlán. Los Anaya no pertenecían a la elite local, pero a través de su matrimonio contraído en 1759 con María Ignacia González Ruvalcaba y González Hermosillo, emparentó con dos de las familias más antiguas y con larga trayectoria en la cría de ganado en la zona. Desde el siglo xvı los González de Ruvalcaba eran dueños de grandes extensiones al oriente de Lagos, con haciendas como El Horno y Carrión mientras que los González Hermosillo tenían un papel equivalente en Jalostotitlán.

A la llegada de Arriola Juan de Anaya, era dueño del sitio de San Nicolás y de la hacienda de El Salto al sur del distrito. Tanto él como sus hermanos se distinguieron como exitosos administradores de los diezmos de la Catedral de Guadalajara. Desde 1770 y durante más de una década, Juan dirigió sus esfuerzos a la recolección de las rentas decimales del partido de Lagos lo que le permitió, además de buenos rendimientos, conocer la dinámica productiva de la región ${ }^{80}$ y al mismo tiempo participaba de los beneficios de las rentas decimales de Tepatitlán en calidad de fiador de don José Igna-

${ }^{78}$ APSML, Bautismos, vol. 16, s/f. En 1753 el dean de la catedral de Guadalajara, doctor Ginés Gómez Parada bautizó en la parroquia de Lagos a una de las hijas de Meza y Bueańo.

${ }^{79}$ Beatriz Rojas, Las instituciones de gobierno, p. 124.

${ }^{80}$ AAG, Archivo Histórico del Cabildo Eclesiástico de Guadalajara (AHCEG), Libro Capitular 12, f. 146f-v. 
cio Sanromán, también vecino de Lagos. Su hermano José Antonio Anaya, por su parte, administraba los diezmos del Nuevo Reino de León y los del Real de Charcas, empresa en la que estaban comprometidos como sus fiadores los hermanos Juan Antonio e Ignacio González de Ruvalcaba, este último regidor capitular de la villa de Lagos. ${ }^{81}$ Al otro de los hermanos Anaya, de nombre José Francisco, el cabildo catedralicio le dio en administración durante varios ańos los otros dos diezmatorios de la meseta alteńa, Jalostotitlán y Teocaltiche. ${ }^{82}$

Los numerosos negocios y actividades de Juan de Anaya y su prestigio entre los regidores laguenses le valieron su elección como alcalde ordinario en varias ocasiones a partir de 1778. Este ingreso a la corporación municipal reforzó su integración en la redes de las familias de la elite laguense donde ya contaba con varios compadres. Finalmente, su amplia red de relaciones, que rebasaba los límites de locales, lo convertía en un personaje de interés para ser reclutado por el titular de la alcaldía y establecer un vínculo que se fortaleció con el tiempo hasta llegar a convertirse en una amistad muy cercana que se mantuvo hasta la muerte de Arriola. Durante su ejercicio como teniente, Juan de Anaya combinó sus tareas como auxiliar del alcalde en la villa, con el cuidado de sus negocios pues consiguió diversas mercedes y obtuvo sentencias favorables para sí mismo y para sus parientes. No es casual que al poco tiempo de haber ingresado al cabildo, su hermano José Antonio lograra una merced de agua que incluía la licencia para un molino y para construir una presa en su hacienda de Santa Inés de Buenavista. ${ }^{83} \mathrm{El}$ mismo teniente logró extender sus propiedades en 1785 con una sentencia favorable que le otorgó doce de caballerías de tierra localizadas entre las haciendas de El Horno y Santa Teresa a pesar de la oposición presentada por uno de los colindantes. ${ }^{84}$

La elección de Félix José de Prido como teniente general permitió a Arriola contar con el apoyo de un jurista. La legislación establecía que los gobernadores de provincia que no fueran letrados

\footnotetext{
${ }^{81}$ AAG. AHCEG, Gobierno, Diezmos, exp. 39, caja 14.

${ }^{82}$ AAG. AHCEG, Libro Capitular 12, f. 233v; AAG. AHCEG, Libro Capitular 13, f. 90v.

${ }^{83}$ AIPJ, TA, vol. 44, exp. 14, f. 133 f.

${ }^{84}$ AIPJ, TA, leg. 73, vol. 294, exp. 8, ff. 1-14.
} 
debían nombrar tenientes con tal formación. Dada la escasez de personal con formación en derecho en el Nuevo Mundo no se pudo cumplir con esta condición salvo en las ciudades más importantes. Por ello, la mayoría de los alcaldes mayores recurrieron a la práctica de integrar los expedientes para enviarlos a un letrado para su consulta cuando los asuntos requerían su parecer. La presencia de Prido, abogado de las Reales Audiencias, que gozó de "nombramiento público" como teniente general del alcalde mayor desde 1777 , es una prueba de que la población y el número y calidad de asuntos que se ventilaban en el juzgado del alcalde mayor habían aumentado significativamente. Como teniente general, Prido recibió informaciones, expidió testimonios e integró causas a nombre del titular y seguramente actuó como asesor letrado en los asuntos del alcalde que requerían su parecer. ${ }^{85} \mathrm{Su}$ participación en asuntos de tierras y aguas fue frecuente, destacando en medidas de $\operatorname{tierras}^{86} \mathrm{y}$ en especial en el litigio que involucró a Juan de Anaya. ${ }^{87}$

El alcalde mayor de Santa María de los Lagos debía gobernar su provincia en estrecha colaboración con el cabildo local debido a la jurisdicción extensa que detentaba como privilegio especial esta corporación. Esta circunstancia especial hacía necesario establecer acuerdos para mantener un precario equilibrio entre los dos ámbitos jurisdiccionales. El alcalde mayor debía presidir las sesiones del cabildo y regimiento de la villa y en este espacio surgían relaciones, mismas que se ven reflejadas en los testimonios e informaciones referente a los 48 alcaldes ordinarios, regidores, procuradores y escribanos que estuvieron en funciones a lo largo de los primeros diez años de gobierno de Arriola y que aparecen mencionados en el juicio de residencia que éste presentó en 1789 (véase figura 2).

Tampoco se puede olvidar a las autoridades eclesiásticas con quienes los representantes del monarca compartían espacios de poder que el regalismo borbónico había modificado. A este respecto puede observarse que en momentos en los que eran frecuentes los conflic-

\footnotetext{
${ }^{85}$ Woodrow Borah, El gobierno provincial, pp. 55-56.

${ }^{86}$ AIPJ, TA, leg. 77, vol. 301, exp. 5, ff. 1-20.

${ }^{87}$ AIPJ, TA, leg. 73, vol. 294, exp. 8, ff. 1-14.
} 

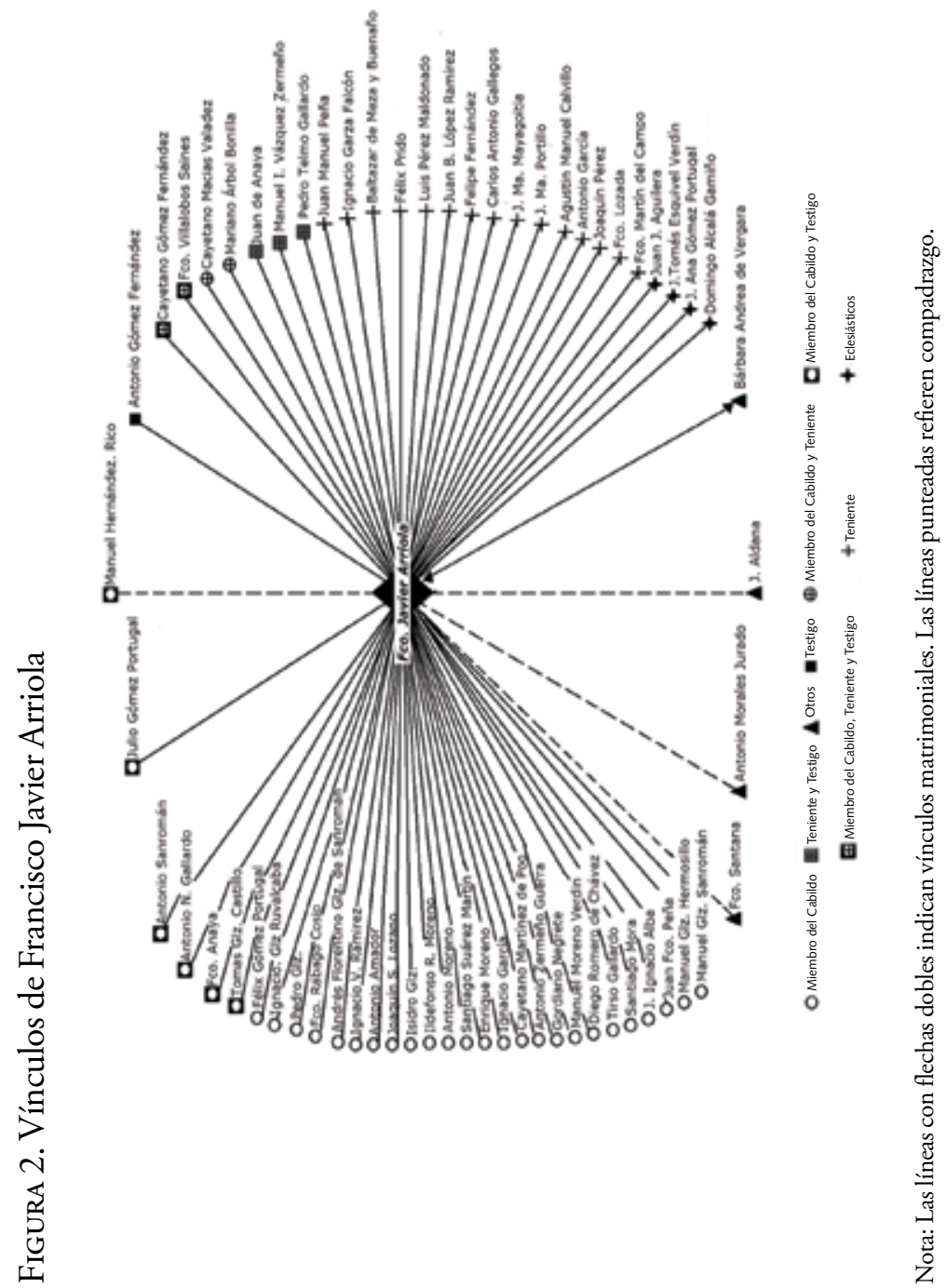
tos entre el poder temporal y el poder espiritual, Arriola puso especial empeńo para ganarse el apoyo del clero como benefactor de diversas causas y especialmente al mandar edificar un "famoso santuario” dedicado a Jesús Nazareno bajo la advocación del Calvario, además de socorrer con sus limosnas al convento de las religiosas capuchinas de la villa, donde costeaba anualmente una misa con sermón el día de la fiesta de San Juan Nepomuceno a la que asistían ambos cleros y demás personas de distinción del lugar.

Francisco Javier Arriola y su mujer no tuvieron descendencia, por tanto sus vínculos familiares debieron quedar en Cuba. Sin embargo, los lazos de parentesco espiritual, vínculos fuertes en una sociedad tradicional, estuvieron presentes desde los primeros años de su llegada a Lagos. Los nombres de los padres de los niños que apadrinó el alcalde mayor siempre van antecedidos del calificativo de "don" y "doña" que señalan su pertenencía a las familias reconocidas por su antigüedad, riqueza y prestigio en la región. Así, en 1775 se convirtió en compadre de don José de Aldana y don Antonio Montes Jurado. En 1793, ya como justicia mayor, llevó a la pila bautismal a una hija de don Francisco Santana y dońa Petra Moreno que murió a los pocos meses. Para mantener el vínculo esta pareja volvió a invitarlo como padrino de otra nińa nacida al ańo siguiente. En ese mismo año contraería el mismo parentesco con don Manuel Hernández Rico y su mujer, dońa Josefa Román.

Para 1792, el justicia mayor decidió que había llegado el momento de buscar la recompensa que en su concepto merecían su dedicación y amor al real servicio y para ello se dirigió al monarca solicitando la promoción a un distrito con mayor salario o bien un nombramiento de capitán de ejército. Para acreditar sus méritos Arriola movilizó su capital relacional para apoyar su solicitud, como se aprecia en el expediente que presentó con las declaraciones de doce vecinos y siete de los clérigos de la parroquia. Estos testimonios revelan quiénes eran los allegados del magistrado, cuya cercanía les lleva a expresarse decididamente a su favor. Entre los testigos llamados a declarar estaban tanto aquellos con quienes tenía vínculos de amistad, como Juan de Anaya y Pedro Telmo Gallardo, como su compadre Manuel Hernández Rico y representantes del sector más 
influyente de la elite local como los regidores Manuel Ignacio Vázquez Zermeño, José Francisco Villalobos Saines, Cayetano Gómez Fernández, Antonio Sanromán y José Julio Gómez Portugal.

Todos ellos declararon que el alcalde mayor había ejercitado su oficio "con mucha legalidad, pureza y fidelidad, en que ha dado un claro conocimientos de su ver opuesto a los intereses humanos, desempeñando con el honor que naturalmente acostumbra los oficios de buena administración de justicia, sin agravio de partes". Los hermanos Francisco y Juan Anaya lo señalaron como juez imparcial y afirmaron que era muy caritativo y piadoso con los pobres y había procedido con moderación, madurez y buen arreglo, por ser de una vida recogida, juiciosa y cristiana. El entusiasmo del segundo resulta especialmente notorio cuando afirma que el magistrado se había ganado la mayor estimación del común de toda la jurisdicción por la moderación y madurez con que procedía en todas las materias, que era de muy buena vida, de cristianos procedimientos y buenas costumbres. ${ }^{88}$

Los miembros del clero, por su parte, no escatimaron elogios al decir que se distinguía por su caridad y compasión a las viudas y a los pobres, "procurando como verdadero padre de la república solicitar en las necesidades el socorro de los menesterosos" y que en ocasión de las pestes y enfermedades que se habían presentado en 1786 había tratado de reparar los daños a sus expensas y aun sacrificando sus propios intereses.

Arriola aspiraba a la alcadía mayor de Xicayan o la de Villalta, en Oaxaca, lugares reconocidos por rendir pingües ganancias generadas en el comercio trasatlántico de sus productos, pero la Corona respondió que esos gobiernos estaban ocupados y que estaba mandado que no se concedieran grados ni jubilación militar a quien había recibido empleos políticos. Francisco Javier Arriola terminó sus días en la villa de Santa María de los Lagos donde fue sepultado el 5 de mayo de 1799 con toda solemnidad, en ceremonia con cruz alta y dalmática, en el convento de la Merced. Su partida de entierro señala que para entonces era viudo de dońa Bárbara Andrea Verga-

${ }^{88}$ AGs. SGU, 6966, exp. 8, f. 9v-10f. 
$\mathrm{ra}^{89}$ y que había dictado testamento en 1797 nombrando como albaceas a las dos personas que formaban su entorno más cercano y con quienes le unía una estrecha relación desde hacía tiempo, su antiguo teniente Juan de Anaya y el regidor y vecino de la villa Luis Moreno de Ortega.

El caso de Francisco Javier Arriola en Santa María de los Lagos llama la atención sobre la necesidad de conocer las condiciones que se presentaron en la Intendencia de Guadalajara durante el proceso de transformación de las alcaldías mayores en subdelegaciones, pues, aquí aparecen particularidades que requieren comparación con lo ocurrido en otros distritos.

El número de vínculos que se registran en el gráfico 2 da cuenta de la existencia de una elite más extensa, representativa de una población más numerosa y un territorio más amplio que aquellos que había encontrado Otaduy a su llegada. En el caso del militar cubano y la constelación de relaciones que tejió con sus gobernados no fue suficiente para conseguir su objetivo de escalar a nuevos empleos en momentos de cambio de políticas de la monarquía, a cambio, le garantizó un largo periodo en el servicio real como titular del distrito alteño.

La reconstrucción de los vínculos de los dos alcaldes de la jurisdicción de Lagos estudiados y su representación gráfica permite observar que a su llegada a un distrito los representantes de la Corona procedentes de la metrópoli tenían necesidad de insertarse en las redes locales para realizar con éxito sus tareas. De la capacidad del magistrado para establecer vínculos con integrantes de la elite podía depender su supervivencia y continuidad en el cargo. Las dificultades para establecer alianzas y poder integrarse en las redes de los mineros zacatecanos constituyeron un serio obstáculo para que Otaduy y Avendaño ejerciera las tareas de corregidor de esa ciudad.

Por otra parte, era la existencia de vínculos de confianza, compadrazgo y clientela la que permitía el intercambio de bienes y servicios entre los magistrados y los habitantes de los distritos bajo su jurisdicción y contribuía a la legitimidad y aceptación de la autori-

${ }^{89}$ Archivo Parroquial de Santa María de los Lagos (APSML), Entierros, vol. 13, f. 46v-47f. 
dad de los alcaldes mayores porque era a través de ellos que se lograban los equilibrios entre los intereses locales y los intereses de la monarquía. Estos lazos permitían al magistrado iniciar la construcción de su propia red, inserta en las sociabilidades de la población local y convertirse en centro de una trama de dependencias y solidaridades recíprocas que favorecía la extracción de recursos y el establecimiento de una red de explotación regional en la que se compartían los beneficios y se aseguraban complicidad y discreción.

Las condiciones en que se desempeñaba el oficio de alcalde mayor hacían necesario el establecimiento de relaciones de confianza entre el representante de la Corona y sus gobernados. El magistrado requería fianzas y garantías que no siempre podía conseguir en su lugar de origen o en la capital del reino, así como asistentes y colaboradores para el desarrollo de sus funciones y para asegurar una compensación económica que el salario no podía proporcionar. Para los habitantes del distrito era indispensable contar con su apoyo y colaboración para asegurar la buena marcha de sus empresas, la atención a sus demandas y el desarrollo de los diversos negocios y peticiones que requerían de su intermediación ante las autoridades del reino. Aun cuando se trató de individuos recién desembarcados en territorio neogallego, desde el primer momento la coincidencia de intereses entre ambas partes permitía establecer compromisos y solidaridades de beneficio mutuo.

Se percibe también la amplitud y variedad de solidaridades entre los funcionarios reales, los regidores, alcaldes del cabildo y la elite local. Relaciones de muy diversos signos y propósitos entre las que se incluyen confianza, clientelismo, compadrazgo, negocios y amistad, sin las cuales un magistrado no hubiera podido continuar su carrera. Llama la atención la permanencia de los vínculos, que no desaparecen una vez que el magistrado sale del distrito o concluye su periodo en el oficio. Otaduy logró nuevos cargos con la fianza de sus compadres laguenses y Arriola recurría al testimonio de sus aliados y colaboradores para sostener su petición a una nueva alcaldía.

Los dos casos presentados muestran que los magistrados que llegaban a las Indias recién nombrados empezaban a tejer una red de relaciones desde el primer momento. Ambos arribaron casados 
y uno de ellos no tuvo descendencia, por tanto hay poca información. Aun cuando el modelo previsto por la legislación buscó que se mantuviera una distancia entre los representantes de la justicia y sus gobernados para garantizar su imparcialidad y recta administración, la realidad fue distinta y tal como ocurría en otros niveles, se puede decir que alcaldes mayores y subdelegados no dudaron en poner al servicio de sus compadres y aliados su autoridad y competencia. ${ }^{90}$

La capacidad política y económica de la elite se expresa en el monopolio que ejerce sobre el cabildo, los diezmos y la exportación de ganado. Poco más de una docena de familias controlan la producción de cereales y el comercio de ganado en haciendas que abastecían principalmente a los reales de minas del norte novohispano. Entre los miembros de estas familias y los representantes de la Corona se desarrollaron estrategias para establecer relaciones de beneficio mutuo para la explotación de los recursos y el control de los espacios de autoridad, cuya pervivencia es prueba de su eficacia hasta la última década del siglo XviII.

Los vínculos que se establecían entre las familias de la elite política y económica de Santa María de los Lagos y sus alcaldes mayores fueron vínculos fuertes según lo demuestran las evidencias que se han podido rastrear a través de las fianzas, el tenientazgo y el parentesco espiritual. Estos vínculos lejos de disminuir con la llegada de gobernantes nombrados desde la Península, se mantuvieron y aún se volvieron más necesarios dado el interés de éstos por recuperar la inversión que representaba la adquisición del título y el viaje trasatlántico, y el de la población local por asegurar y aumentar el rendimiento de sus empresas ganaderas, agrícolas y comerciales. Por otra parte, la presencia de un cabildo fuerte y el desconocimiento del terreno que acusaban los gobernantes provinciales recién llegados se combinaron a favor de los intereses locales.

Las palabras de un funcionario de la Real Audiencia que escribe al monarca en 1693 dibujan con claridad las circunstancias que rodeaban a los justicias en sus distritos:

${ }^{90}$ Michel Bertrand, Grandeur et misère de l'office, p. 408. 
Si se acusa a cualquiera de estos justicias resulta que tienen algunos vecinos a su favor y la población se divide y enemista mortalmente, sembrando rencores que duran más allá de la salida del acusado, unos tratando de destruir al capitulado y otros a favorecerlo, deshonrándose unos y otros, alegando defectos y aún inventando otros y si se le acusa en la Audiencia o les fulmina a sus acusadores por delitos que antes les había tolerado o les imputa otros por desquite, generándose ruidos y escándalos quedando los vecinos entre odios y venganzas [...] [como se observa con] Otaduy y Avendaño alcalde mayor que ha sido de la villa de los Lagos en cuya averiguación está entendiendo ministro togado por haber reservándose aquellos [vecinos] para la residencia que actualmente está dando. ${ }^{91}$

\section{BiBLIOGRAFÍA}

Becerra Jiménez, Celina G, Oficios de justicia en una sociedad ganadera de la Nueva Galicia. Santa María de los Lagos. 1563-1750. Tesis del Programa de Doctorado en Ciencias Sociales, El Colegio de Michoacán, 2004.

Gobierno, justicia e instituciones en la Nueva Galicia. La alcaldia mayor de Santa María de los Lagos, Guadalajara, Universidad de Guadalajara, 2008.

, "Familia y vínculos en un cabildo neogallego. Santa María de los Lagos. 1600-1750", en Manuela Cristina García Bernal y Sandra Olivero Guidobono, coords., El municipio indiano: relaciones económicas y sociales. Homenaje a Luis Navarro García, Sevilla, Universidad de Sevilla, 2009, 69-89.

BoraH, Woodrow, El gobierno provincial en la Nueva España. 15701787, México, Universidad Nacional Autónoma de México, 1985. Calvo, Thomas, "Círculos de poder en la Guadalajara del siglo XviI" en Familia y poder en Nueva España, México, Instituto Nacional de Antropología e Historia, 1991, 103-113.

Poder, religión y sociedad en la Guadalajara del siglo XVII, México, Centre d'Études Mexicaines et Centraméricaines, $\mathrm{H}$. Ayuntamiento de Guadalajara, 1992.

\footnotetext{
${ }^{91}$ AGI, Guadalajara, 40, núm. 41.
} 
Clavero, Bartolomé, Razón de estado, razón de individuo, razón de historia, Madrid, Centro de Estudios Constitucionales, 1991.

Castillo de Bovadilla, Jerónimo, Politica para corregidores y vasallos en tiempos de pazy de guerra y para jueces eclesiásticos y seglares $y$ de sacas de aduana $y$ de residencias y sus oficiales y para regidores $y$ abogados y del valor de los corregimientos y gobiernos realengos y de las órdenes.... 2 vols., Madrid, Imprenta Real, 1649.

Enciso Contreras, José, "Decretos inhibitorios, justicia privativa provincial y local. El caso del conde de Santa Rosa en Zacatecas, s. XVIII", en Derecho, instituciones y procesos históricos: XIV Congreso del Instituto Internacional de Historia del Derecho Indiano, José de la Puente Brunke y Jorge Armando Guevara Gil, coords, vol. 2, Lima, Pontificia Universidad Católica del Perú-Instituto Riva-Agüero, 2008, 377-396.

GÁlVEZ, Ma. de los Ángeles, La conciencia regional en Guadalajara y el gobierno de los intendentes. 1786-1800, Guadalajara, UNED, 1996.

Garriga, Carlos, "Orden jurídico y poder político en el Antiguo Régimen”, Istor. Revista de Historia Internacional, año IV, núm. 16, primavera 2004, 13-44.

GuARDIOLA, Lorenzo, El corregidor perfecto y juez dotado de las calidades necesarias y convenientes para la recta administración de justicia..., Madrid, Imprenta de Alfonso López, 1785.

Hespanha, Antonio Manuel, Visperas del Leviatán. Instituciones y poder politico (Portugal, siglo XVII), versión castellana de Fernando Jesús Bouza Álvarez, Madrid, Taurus Alfaguara, 1989.

, Cultura jurídica europea. Sintesis de un milenio, Madrid, Tecnos, 2002.

Jiménez Pelayo, Agueda, "La carrera política de un gallego en Nueva España. Manuel Vaamonde: de alcalde mayor de Sayula a gobernador del Nuevo Reino de León y Tlaxcala” en Celina G. Becerra Jiménez, coord., Elites, redes y vínculos en el Centro Occidente de México, Guadalajara, Universidad de Guadalajara, 2008. Menegus, Margarita, comp., El repartimiento forzoso de mercancías en México, Perú y Filipinas, México, Instituto Mora, unam, CESU, 2000.

Muro Romero, Fernando, "El beneficio de oficios públicos con 
jurisdicción en Indias. Notas sobre sus orígenes", Anuario de Estudios Americanos, xxxv, Sevilla, 1978, 1-67.

Palomo Sousa, Carmen Paula, "Los corregidores de Zacatecas: una elite de poder (1700-1786)" en Luis Navarro García, coord., Elites urbanas en Hispanoamérica (De la conquista a la independencia), Sevilla, Universidad de Sevilla, 2005, 115-132.

Phelan, John Leddy, The Kingdom of Quito in the Seventeenth Century: Bureaucratic Politics in the Spanish Empire, Madison, The University of Wisconsin Press, 1967.

Piestchmann, Horst, "Burocracia y corrupción en Hispanoamerica colonial. Una aproximación tentativa en Jochen Meixner, Renate Pieper y Peer Schmidt, comps., Mexiko zwischen Reform un Revolution vom bourbonischen Zeitalter zur Unabhängigkeit, Stuttgart, Steiner, 2000, 143-169.

, Las reformas borbónicas y el sistema de intendencias en Nueva España, México, Fondo de Cultura Económica, 1996.

ReEs Jones, Ricardo, El despotismo ilustrado y los intendentes de la Nueva España, México, Universidad Autónoma de México, 1979. Rojas, Beatriz, Las instituciones de gobierno y la elite local. Aguascalientes del siglo XVII hasta la Independencia, Zamora, El Colegio de Michoacán, Instituto Mora, 1998.

Romero de Solís, José Miguel, Conquistas e instituciones de gobierno en Colima de la Nueva España (1523-1600), Colima, Archivo Histórico del Municipio de Colima, Universidad de Colima, El Colegio de Michoacán, 2007.

SAnz TAPIA, Ángel, ¿Corrupción o necesidad? La venta de cargos de Gobierno americanos bajo Carlos II (1674-1700), Madrid, Consejo Superior de Investigaciones Científicas, 2009, 53-54.

Socolow, Susan, The Bureaucrats of Buenos Aires, 1769-1810: Amor al Real Servicio, Durham, Duke University Press, 1987.

\section{Archivos Consultados}

AAg Archivo del Arzobispado de Guadalajara.

AAG. AHCEg Archivo del Arzobispado de Guadalajara. Archivo Histórico del Cabildo Eclesiástico de Guadalajara. 
AGI Archivo General de Indias, Sevilla.

Ags Archivo General de Simancas, España.

Ags. SGU Archivo General de Simancas, España. Secretaria del Despacho de Guerra.

AIPJ Archivo de Instrumentos Públicos del Estado de Jalisco.

Protocolos de Notarios. JLR Protocolos de José López Ramírez.

JaC Protocolos de José Antonio Calleja.

MTA Protocolos de Miguel Tomás de Ascoide.

AIPJ. Gob. Archivo de Instrumentos Públicos del Estado de Jalisco.

Libros de Gobierno.

AIPJ. TA Archivo de Instrumentos Públicos del Estado de Jalisco.

Ramo Tierras y Aguas.

ARA-Civil, Archivo de la Real audiencia de Guadalajara. Ramo Civil. APSML Archivo Parroquial de Santa María de los Lagos.

Fecha de ReCepción del artículo: 19 de julio de 2011

FECHA DE ACEPTACIÓN Y RECEPCIÓN DE LA VERSIÓN FINAL: 15 de diciembre de 2011 